\title{
Clarifying the molecular mechanism of tomentosin-induced antiproliferative and proapoptotic effects in human multiple myeloma via gene expression profile and genetic interaction network analysis
}

\author{
PATRIZIA VIRDIS ${ }^{1 *}$, ROSSANA MIGHELI ${ }^{1 *}$, VALENTINA BORDONI ${ }^{2}$, FRANCESCO PAOLO FIORENTINO $^{3}$, \\ LUCA SANNA $^{1}$, IRENE MARCHESI ${ }^{3}$, GIORGIO PINTORE ${ }^{4}$, GRAZIA GALLERI ${ }^{1}$, MARIA ROSARIA MURONI ${ }^{1}$, \\ LUIGI BAGELLA $^{2,5}$, CLAUDIO FOZZA ${ }^{1}$, MARIA ROSARIA DE MIGLIO ${ }^{1}$ and LUIGI PODDA ${ }^{1}$ \\ Departments of ${ }^{1}$ Medical, Surgical and Experimental Sciences and ${ }^{2}$ Biomedical Sciences, University of Sassari; \\ ${ }^{3}$ Kitos Biotech Srls, Porto Conte Ricerche; ${ }^{4}$ Department of Chemistry and Pharmacy, University of Sassari, \\ I-07100 Sassari, Sardinia, Italy; ${ }^{5}$ Sbarro Institute for Cancer Research and Molecular Medicine, Center for Biotechnology, \\ College of Science and Technology, Temple University, Philadelphia, PA 19122, USA
}

Received June 25, 2021; Accepted September 2, 2021

DOI: $10.3892 / \mathrm{ijmm} .2021 .5046$

\begin{abstract}
Multiple myeloma (MM) is an aggressive B cell malignancy. Substantial progress has been made in the therapeutic context for patients with MM, however it still represents an incurable disease due to drug resistance and recurrence. Development of more effective or synergistic therapeutic approaches undoubtedly represents an unmet clinical need. Tomentosin is a bioactive natural sesquiterpene lactone extracted by various plants with therapeutic properties, including anti-neoplastic effects. In the present study, the potential antitumor activity of tomentosin was evaluated on the human RPMI-8226 cell line, treated with increasing tomentosin concentration for cytotoxicity screening. The data suggested that both cell cycle arrest and cell apoptosis could explain the antiproliferative effects of tomentosin and may result in the inhibition of RPMI-8226 cell viability. To assess differentially expressed genes contributing to tomentosin activity and identify its mechanism of action, a microarray gene expression profile was performed, identifying 126 genes
\end{abstract}

Correspondence to: Professor Maria Rosaria De Miglio or Professor Claudio Fozza, Department of Medical, Surgical and Experimental Sciences, University of Sassari, 43B Viale San Pietro, I-07100 Sassari, Sardinia, Italy

E-mail: demiglio@uniss.it

E-mail: cfozza@uniss.it

*Contributed equally

Key words: multiple myeloma, tomentosin, cytotoxicity, apoptosis, gene expression profiling, cyclic AMP-dependent transcription factor ATF-4, DNA damage-inducible transcript 3 protein, Protein-Protein Interaction network deregulated by tomentosin. To address the systems biology and identify how tomentosin deregulates gene expression in MM from a systems perspective, all deregulated genes were submitted to enrichment and molecular network analysis. The Protein-Protein Interaction (PPI) network analysis showed that tomentosin in human MM induced the downregulation of genes involved in several pathways known to lead immune-system processes, such as cytokine-cytokine receptor interaction, chemokine or NF- $\mathrm{KB}$ signaling pathway, as well as genes involved in pathways playing a central role in cellular neoplastic processes, such as growth, proliferation, migration, invasion and apoptosis. Tomentosin also induced endoplasmic reticulum stress via upregulation of cyclic AMP-dependent transcription factor ATF-4 and DNA damage-inducible transcript 3 protein genes, suggesting that in the presence of tomentosin the protective unfolded protein response signaling may induce cell apoptosis. The functional connections analysis executed using the Connectivity Map tool, suggested that the effects of tomentosin on RPMI-8226 cells might be similar to those exerted by heat shock proteins inhibitors. Taken together, these data suggested that tomentosin may be a potential drug candidate for the treatment of MM.

\section{Introduction}

Multiple myeloma (MM) is a B cell malignancy of transformed plasma cells derived from mature post-follicular B cells that occurs in older individuals with a median age at diagnosis of 69 years and a median overall survival (OS) of 6-7 years $(1,2)$. The disease is the second most common hematological malignancy in high-income countries and its development usually starts with a monoclonal gammopathy of undetermined significance (MGUS), followed by smoldering MM and finally the full MM disease emerges (3). Progression affects a succession of genetic events and bone marrow (BM) microenvironment modifications, such as induction of angiogenesis, suppression 
of cell-mediated immunity and development of paracrine signaling loops (such as IL6 and VEGF) (4). Myeloma cells release cytokines that induce osteoclast activity and bone resorption. The increased bone resorption in turn causes the release of growth factors that stimulate myeloma cells, thus establishing a vicious cycle $(5,6)$. A marked increase in osteoclast activity leading to bone destruction characterizes MM (5). Patients with symptomatic MM usually show an increase of calcium, renal insufficiency, anemia or bone lesions defined as CRAB criteria (7).

Although MM is still an incurable blood cancer, prognosis today has considerably improved compared with in past years, and in the last two decades overall response rates (ORR), progression-free survival (PFS) and OS have improved (1). Between 2011 and 2014, the risk of death in patients with a new diagnosis of MM was 35\% lower than between 2006 and 2010 (8). Novel agents and combination therapies, including proteasome inhibitors (PIs), immunomodulators (IMiDs), anti-human CD38 (daratumumab) $(9,10)$, autologous stem cell transplantation (ASCT) (11) and maintenance therapy (12) have improved OS rates compared with historical approaches based on steroids and chemotherapy (13).

Recently, novel agents such as chimeric antigen receptor $\mathrm{T}$ cell and Bi-specific antibodies associated with old and new drugs have led to a further improvement in the survival of these patients (14). In this scenario of combined therapies, the risk of adverse events is increased, thus making it even more critical to carefully monitor patients regarding possible side effects to avoid early complications that may compromise therapeutic outcome (15). Enhancements in OS are not uniform across patients with MM, especially considering ethnic minorities (16) and patients diagnosed at an older age of onset (17). Moreover, MM continues to represent an incurable disease due to the frequent development of drug resistance and its intrinsic tendency to relapse (18). All these considerations explain why the development of more effective or synergistic therapeutic approaches undoubtedly represents an unmet clinical need.

Traditional herbal medicines are a useful reserve of biologically active natural products with therapeutic effects that could be used in the treatment of several diseases, including cancer. Our previous work demonstrated that Inula viscosa extract has a potent anti-lymphoma activity through inhibition of cell proliferation and induction of cell apoptosis, suggesting potential molecular mechanisms that include the downregulation of genes involved in the control of growth and survival pathways, known to be deregulated in Burkitt Lymphoma cells (19). Tomentosin and inuviscolide are sesquiterpene lactones isolated from I. viscosa (L.) Aiton, which has been applied for a long time in traditional medicine for its anti-inflammatory (20), anthelmintic, antipyretic, antiseptic and antiphlogistic activities $(21,22)$ and in the treatment of diabetes (23) and lung disorders (24).

Messaoudi et al (25) performed a chemical composition analysis of different $I$. viscosa extracts from three different regions of Morocco, revealing the presence of sesquiterpene lactones, as well as tomentosin and inuviscolide, as major representative compounds, with tomentosin ranging from 22 to $64 \%$ and inuviscolide ranging from 0 to $58 \%$ (25). Recently, different studies have reported the potential anticancer effects of sesquiterpene lactones, and shown that tomentosin and inuviscolide exert antiproliferative effects on human cancer cell lines (26-29). However, so far, the effects of singular compounds in MM have not been investigated. Based on our previous results showing antitumoral activity of natural extract from I. viscosa on Raji cells, the anti-neoplastic effects of synthetized sesquiterpene lactones, such as inuviscolide and tomentosin, in human MM cell lines were evaluated, with the aim to isolate specific bioactive natural products that could be applied in the treatment of human MM. Moreover, in order to investigate the mechanisms underlying the activity of tomentosin in this specific context, an array-based gene expression analysis was performed.

\section{Materials and methods}

Cell culture. MM.1S and RPMI-8226 were obtained from Dr Marina Ferrarini from San Raffaele Telethon Institute for Gene Therapy (SR-Tiget), San Raffaele Scientific Institute (Milan, Italy). MRC5 cells were obtained from IRCCS University Hospital San Martino-IST National Institute for Cancer Research (Genova, Italy). MM.1S and RPMI-8226 cells were cultured in RPMI-1640 (Euroclone SpA) supplemented with 10\% FBS (Euroclone SpA), 2 mM L-Glutamine (Merck KGaA) and Antibiotic/Antimycotic Solution (Merck KGaA). MRC5 cells were cultured in DMEM high-glucose (Euroclone SpA) supplemented with $10 \%$ FBS, 2 mM L-Glutamine, non-essential amino acids, $1 \mathrm{mM}$ sodium pyruvate (Merck KGaA) and Antibiotic/Antimycotic Solution. Cells were maintained at $37^{\circ} \mathrm{C}$ in a $95 \%$ humidified atmosphere and $5 \% \mathrm{CO}_{2}$ in $\mathrm{T} 25$ filtered-flasks.

Cytotoxicity assay. MM.1S, RPMI-8226 and MRC5 cells were seeded in a 384-multiwell microplate at a concentration of 10,000 (MM.1S) or 1,600 (RPMI-8226, MRC5) cells in $25 \mu \mathrm{l}$ per well. Cells were chosen based on a preliminary proliferation setting assay. The day after, cells were treated with inuviscolide (cat. no. P-25946716; Mcule, Inc.), tomentosin (cat. no. P-25953579; Mcule, Inc.) and cisplatin (cat. no. C2210000; Merck KGaA) at concentrations of $50,25,12.5,6.25,3.125,1.56$ and $0.75 \mu \mathrm{M}$, or with vehicle solution (DMSO $0.5 \%$ ) for $24 \mathrm{~h}$ at $37^{\circ} \mathrm{C}$. Subsequently, cell viability was assessed using CellTox ${ }^{\mathrm{TM}}$ Green Cytotoxicity (cat. no. G8731; Promega Corporation) and CellTiter-Glo (cat. no. G7571; Promega Corporation) assays using sequential multiplex protocol. CellTox Green Dye was added to samples at the same time of treatment at manufacturer's indicated concentrations. Plating of cells, preparation of serial dilutions and addition of compounds to cells were performed using an automated liquid handling platform (Gilson Pipetmax; Gilson). After $48 \mathrm{~h}$ from treatment, GFI was quantified with Cytation 5 (BioTek Instruments, Inc.). For each sample, four images were taken to cover the entire area of the well. Immediately after, CellTiter-Glo luminescent cell viability assay was performed according to the manufacturer's instructions. Relative luminescence units (RLU) were quantified with GloMax Discover (Promega Corporation). All experiments were performed in triplicate. The half maximal inhibitory concentration values were calculated using $\mathrm{R}$ software version 3.2.2 (loess/approx functions) (30), given 100 to RLU observed in samples treated with vehicle solution and 0 to samples without cells 
(absolute $\mathrm{IC}_{50}$ ). Moreover, the $\mathrm{IC}_{50}$ calculation was performed by using drug concentrations adjusted on compound purity, compound concentrations were multiplied for $0.7 \mathrm{x}$ or $0.93 \mathrm{x}$ for the inuviscolide and tomentosin, respectively, and a corrected analysis was performed.

Apoptotic assay. MM.1S, RPMI-8226 and MRC5 were seeded in a 384-multiwell microplate at the concentration of 20,000 (MM.1S) or 10,000 (RPMI-8226, MRC5) cells in $25 \mu \mathrm{l}$ per well. The day after, cells were treated with Tomentosin at concentrations of $50,25,12.5 \mu \mathrm{M}$, or vehicle solution (DMSO 0.1\%). After 24 h of treatment, Caspase-Glo 3/7 (cat. no. G8090; Promega Corporation), Caspase-Glo 8 (cat. no. G8200; Promega Corporation), or Caspase-Glo 9 (cat. no. G8210; Promega Corporation) assays were performed according to the manufacturer's instructions. Luminescence reading was carried out with GloMax Discover Microplate Reader (Promega Corporation). All experiments were performed in triplicate.

Cell cycle analysis. Cell cycle analysis was performed by seeding $1 \times 10^{6}$ RPMI-8226 cells in $5 \mathrm{ml}$ in T25 flask. After $24 \mathrm{~h}$, cells were treated with tomentosin $25 \mu \mathrm{M}$ or vehicle solution (DMSO 0.05\%). Samples were collected after 6, 8, 12, 18 and 24 h of treatment. Samples were washed in PBS, fixed with $70 \%$ ice-cold ethanol and incubated at $-20^{\circ} \mathrm{C}$ overnight. Fixed cells were washed in PBS and stained with 7-aminoactinomycin (7-AAD; BD Biosciences). DNA content of at least 10,000 cells for sample was evaluated with BD FACSCanto II (BD Biosciences), and values are presented as mean \pm standard deviation (SD) of the percentage of three independent experiments. Data were analyzed with R-Bioc Manager software (flowCore/flowViz package) version 1.56 .0 (31).

Gene expression analysis. To perform gene expression analysis $3 \times 10^{6}$ RPMI-8226 cells were seeded in $15 \mathrm{ml}$ in T75 flask. After $24 \mathrm{~h}$, cells were treated with $25 \mu \mathrm{M}$ tomentosin or with vehicle solution (DMSO 0.05\%). Samples were collected after $8 \mathrm{~h}$ of treatment, before the onset of cell cycle perturbation, considering that the number of cells in the $\mathrm{G} 2 / \mathrm{M}$ phase increases at $12 \mathrm{~h}$ after treatment. Then, the gene expression profile of cells treated with tomentosin before the cell cycle arrest and apoptosis start was investigated. Three biological replicates were performed. Expression of 2,559 cancer-related genes was assessed by high-throughput mRNA quantitation (HTG EdgeSeq Oncology Biomarker Panel, HTG Molecular Diagnostics; PMID. 30327311). Counts were normalized and analyzed using the R-Bioc Manager software (DESeq2 package) version 3.0 (32). Genes with a maximum count value among all samples $<84$, corresponding to $10 \%$ quantile, were considered as low expressed and removed from analysis. Genes with fold-change $>1.5$ or $<0.66$ in treated samples and false discovery rate (FDR) $<0.05$ were considered as differentially expressed genes (DEGs). For Gene Set Enrichment Analysis (GSEA) (33), normalized counts were uploaded into the GSEA-Broad Institute website (PMID. 16199517). The maximum and minimum sizes for gene sets were 500 and 15, respectively. A total of 2,257 gene sets from the Gene Ontology (GO) $(34,35)$ Biological Processes database (c5.bp.v7.1.symbols.gmt) were used as a library for analysis (PMID. 21546393). The statistical significance (nominal
Table $\mathrm{I}_{\text {. }} \mathrm{IC}_{50}$ values of inuviscolide, tomentosin and cisplatin after $48 \mathrm{~h}$ of treatment.

\begin{tabular}{lcrc}
\hline Treatment & Cell line & $\mathrm{IC}_{50}, \mathrm{mM}$ & $\begin{array}{c}95 \% \text { confidence } \\
\text { interval, mM }\end{array}$ \\
\hline Inuviscolide & RPMI-8226 & 42.53 & $39.99-45.60$ \\
& MM.1S & $>50.00$ & $\mathrm{ND}$ \\
Tomentosin & MRC5 & $>50.00$ & $\mathrm{ND}$ \\
& RPI-8226 & 26.14 & $22.82-29.90$ \\
& MM.1S & 26.34 & $24.94-27.73$ \\
Cispaltin & MRC5 & $>50.00$ & ND \\
& RPMI-8226 & 17.05 & $15.14-18.92$ \\
& MM.1S & 8.89 & $8.39-9.42$ \\
& MRC5 & 14.75 & $13.09-16.47$ \\
\hline
\end{tabular}

$\mathrm{ND}$, not detectable.

P-value) of the normalized enrichment score (NES) was estimated by running 1,000 gene set permutations.

Functional classification and pathway analysis of DEGs. The Search Tool for the Retrieval of Interacting Genes (STRING) database (http://www.string-db.org/) was used to investigate the potential function of the 126 DEGs identified in tomentosin-treated MM cells, executing GO enrichment analysis and Kyoto Encyclopedia of Genes and Genomes (KEGG) pathway analysis (36), and to understand how DEGs interact with each other a genetic interaction network was constructed. Terms with FDR-corrected enrichment $\mathrm{P}<0.05$ were considered. KEGG pathway results were displayed using Cytoscape software version 3.8.2 (http://www.cytoscape.org).

The 126 DEGs were submitted to the Connectivity Map online web tool (https://www.broadinstitute.org/connectivitymap-cmap), which supplies a data-driven and systematic approach for discovering associations among genes, chemicals and diseases.

Statistical data analysis. All data are presented as mean \pm SD from experiments in triplicate, and statistical significance between cell lines treated and untreated cells was set at $\mathrm{P}<0.05$. Data analysis was performed by one-way analysis of variance (ANOVA) followed by Tukey's post hoc test for the statistical analysis of cell viability and caspase activity, two-way ANOVA and Tukey's post hoc test were applied for the statistical analysis of cell cycle, using R software, version 3.2.2 (30).

\section{Results}

Cytotoxicity of sesquiterpene lactones on MM cell lines. The first objective was to characterize the effects of various concentrations of synthetized sesquiterpene lactones on the proliferation of two MM and normal fibroblast cell lines (MMS1, RPMI-8226 and MRC5). All cell lines were treated with increasing concentrations of inuviscolide, tomentosin and cisplatin $(50,25,12.5,6.25,3.125,1.56,0.75 \mu \mathrm{M})$ for $48 \mathrm{~h}$ and cell viability was determined. For each cell line the $\mathrm{IC}_{50}$ values of all the three drugs are shown in Table I. 

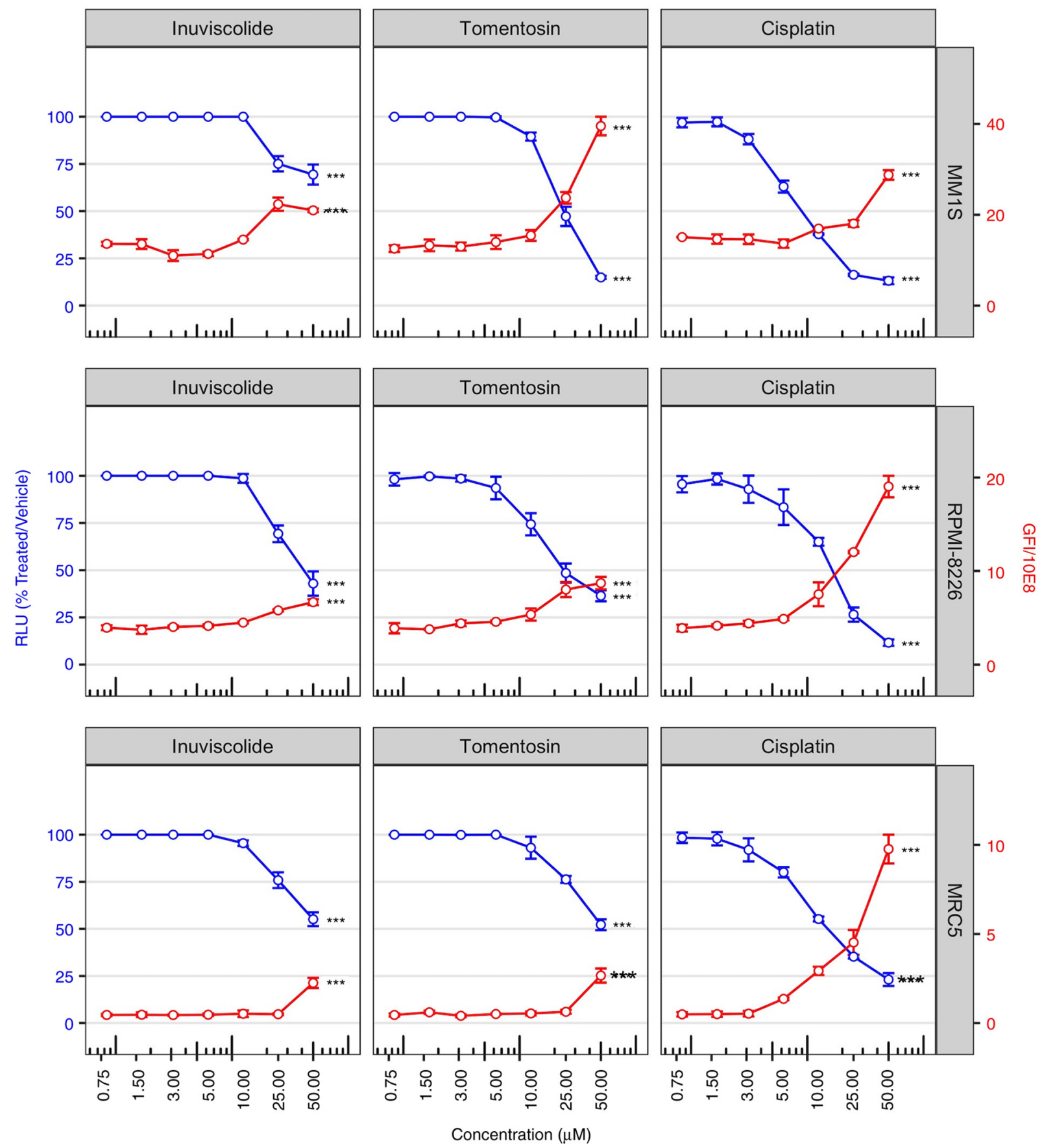

Figure 1. Cell viability is reduced after inuviscolide and tomentosin treatment. Cell viability scatterplots were generated after $48 \mathrm{~h}$ of treatment with inuviscolide, tomentosin or cisplatin at 50, 25, 12.5, 6.25, 3.12, 1.56 or $0.8 \mu \mathrm{M}$. RLU obtained by the addition of CellTiter-Glo reagent and representative of the number of living cells were normalized to samples treated with vehicle solution (left y-axis, blue lines and dots). Total obtained by addition of CellTox green dye and representative of the number of dead cells, was divided by 108 (right y-axis, red lines and dots). Mean \pm SD values are shown. One-way ANOVA was applied. ${ }^{* * *} \mathrm{P}<0.001$. RLU, relative luminescence units.

Fig. 1 shows the impact of dose-dependent cytotoxicity of the drugs on cell viability at $48 \mathrm{~h}$ after treatments (blue lines). Specifically, cell viability assay showed that inuviscolide and tomentosin treatments did not induce changes in cell viability at low concentrations (in the range from 0.75 to $10.0 \mu \mathrm{M}$ ). Whereas, cell viability notably decreased during treatment, inducing cytotoxic effects starting from the concentration of $25.0 \mu \mathrm{M}$, and increasing proportionally the damage with the highest concentration. Specifically, at $50.0 \mu \mathrm{M}$ MM.1S cells showed higher sensitivity to tomentosin than other cell lines, and both MM cell lines at $25.0 \mu \mathrm{M}$ showed higher sensitivity than MRC5. Inuviscolide showed toxicity on MRC5 fibroblasts comparable to or higher than tumor cell lines. These results indicated that tomentosin exerted preferential antiproliferative activity towards both MM cell lines compared with a non-tumor cell line.

In order to assess the amount of cell death caused by drug treatments, selected morphological features were used to label a cell as dead or alive. A primary feature is the disruption of the cell membrane, allowing CellTox Green dye to enter 

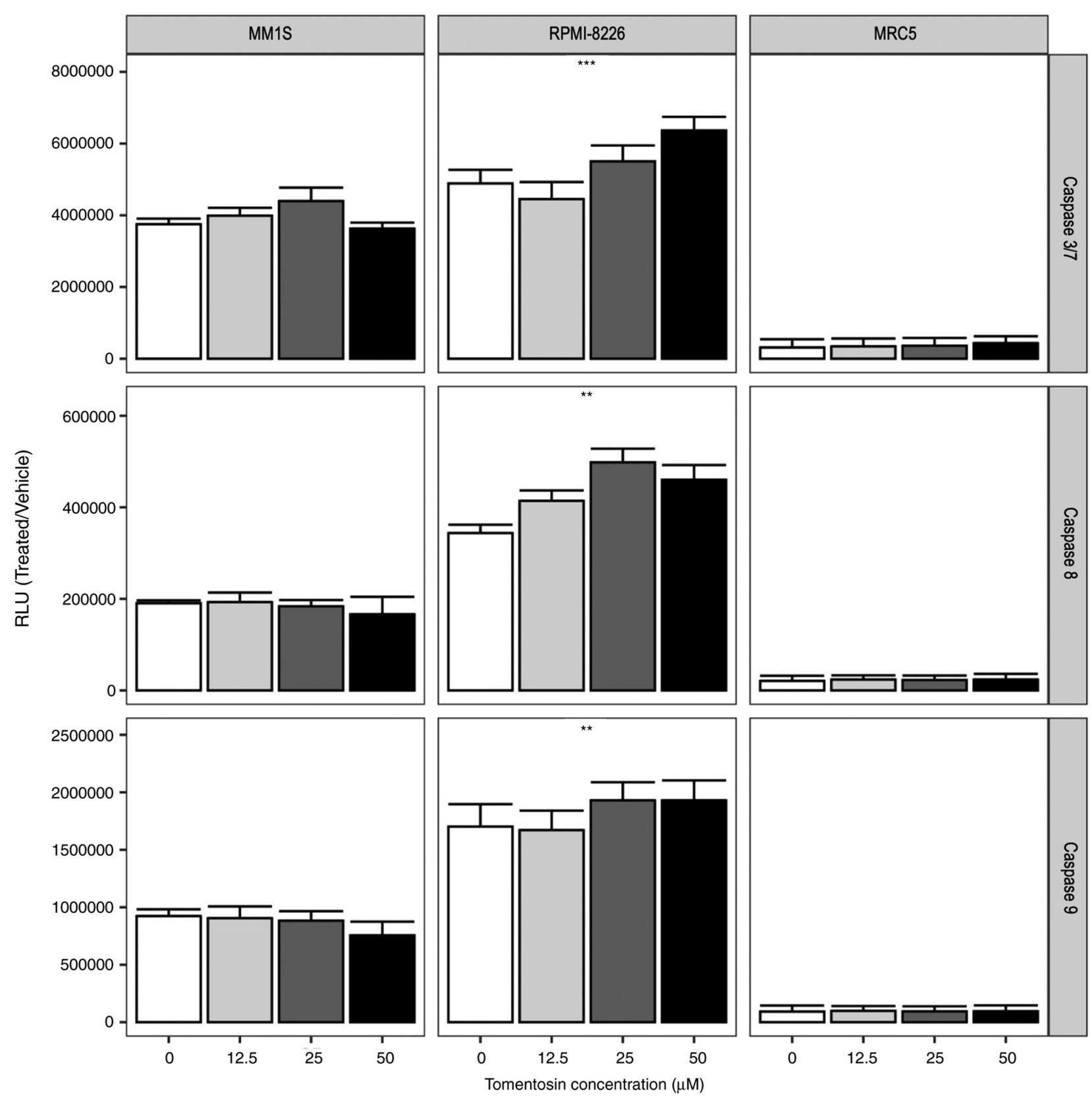

Figure 2. Caspase activities are increased following tomentosin treatment. Histograms showing caspases $3 / 7,8$ or 9 cell-based enzymatic activity after 24 h of treatment with tomentosin at indicated concentrations. Caspase activity in cells treated with vehicle solution is indicated as concentration zero. Mean \pm SD values are shown. One-way ANOVA was applied. ${ }^{* *} \mathrm{P}<0.01$ and ${ }^{* * *} \mathrm{P}<0.001$, tomentosin-treated vs. control. RLU, relative luminescence units.

into the cells and bind to DNA. The observed increase in cell death was in accordance with the proportional decrease in cell viability following the rise of drug concentrations, as shown by a red line in Fig. 1 .

Tomentosin effect on apoptotic cellular processes in MM cell lines. The induction of the apoptotic cascade is one of the main mechanisms of therapy-induced tumor-cell death (37). To determine whether the effects of sesquiterpene lactones depends on its ability to activate the apoptotic cascade, myeloma cell lines were treated with tomentosin at concentrations of $50,25,12.5 \mu \mathrm{M}$ for $24 \mathrm{~h}$. Due to the strong cytotoxicity of inuviscolide on MRC5 fibroblasts, comparable to or higher than the one observed in tumor cell lines, our experiments focused on tomentosin treatment.
The activation of enzymatic activities of the main effector caspases, caspase-3/7 and initiator caspase- 8 and -9 was measured using Caspase-Glo 3/7, 8 and 9 assays. The RLU showed that tomentosin treatment increases caspase activity $(\mathrm{P}<0.05)$, as shown in Fig. 2, and more specifically the effector caspase-3/7 activity was significantly increased in RPMI-8226 cells. Furthermore, the activities of caspase- 8 and -9 , which are representative initiator caspases in the death receptor-mediated and mitochondrial apoptotic pathways, respectively, were also measured, showing a significant increase in RPMI-8226 cells (Fig. 2). Overall, these results suggested that tomentosin promoted apoptosis-induced death on RPMI-8226 cells, mediated by both the death receptor and the mitochondrial pathways. Conversely, non-significant activation of enzymatic activities of caspases were identified in the MM.1S cell line. 
A

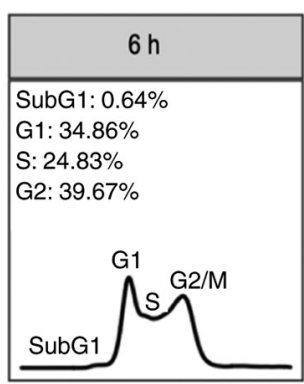

SubG1: $0.84 \%$

G1: $37.43 \%$

S: $24.51 \%$

G2: $37.21 \%$

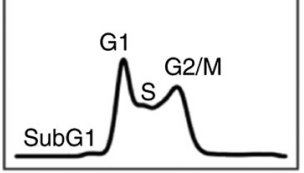

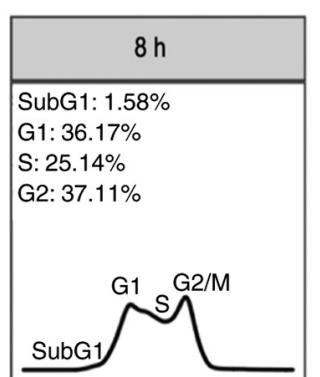
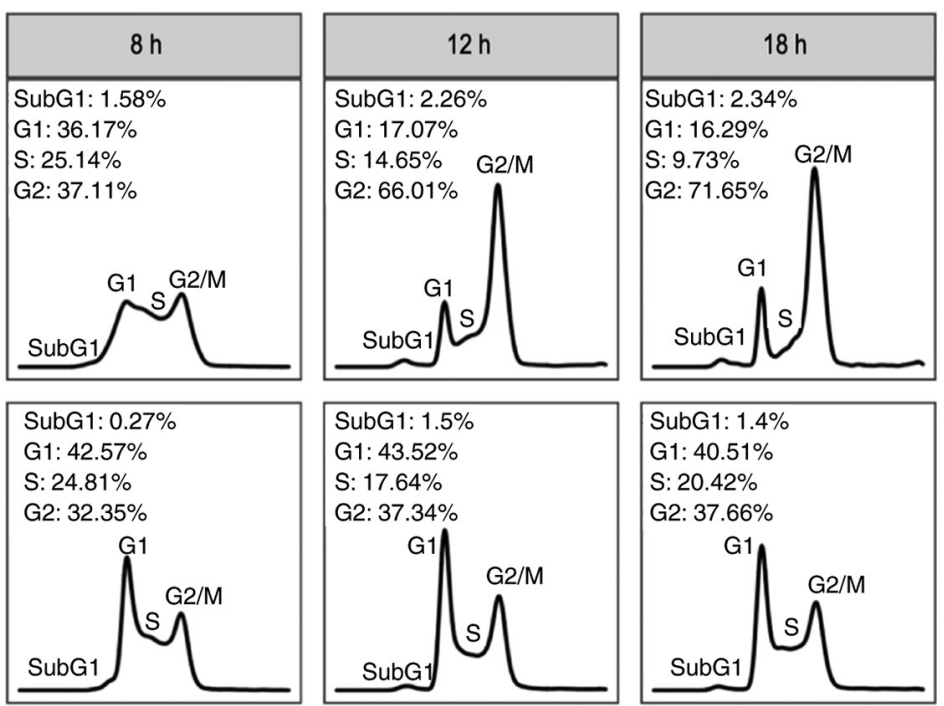

B

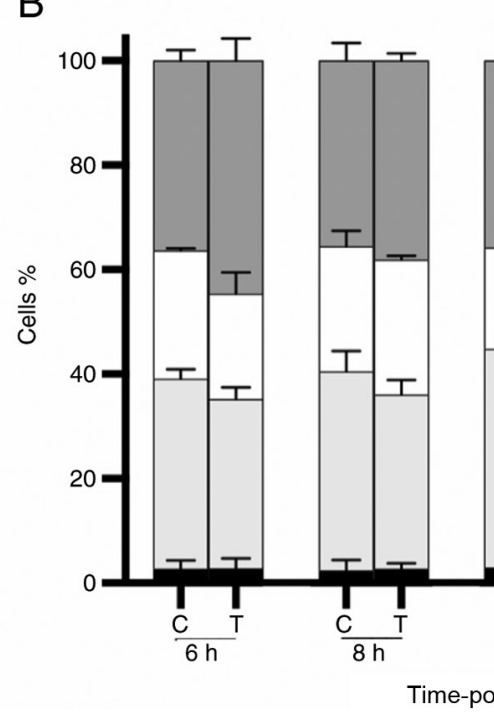

Cell cycle analysis
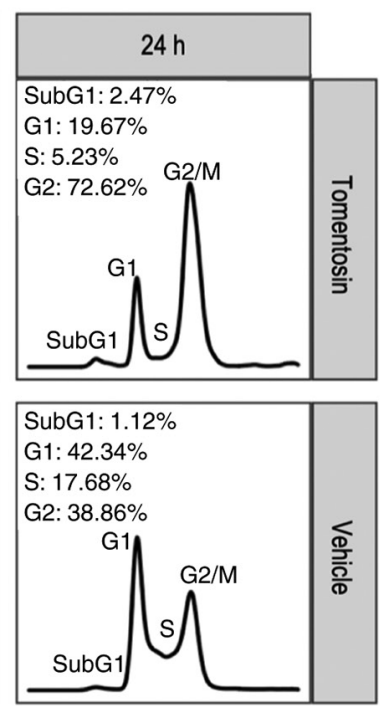

$\square \mathrm{G} 2 / \mathrm{M}$

$\square S$

$\square \mathrm{G} 1$

- SubG1

Figure 3. Effects of tomentosin on cell cycle progression in RPMI-8226 cells. (A) Histograms show cell cycle profiles of tomentosin-treated RPMI-8226 cells. $\mathrm{x}$-axis and $\mathrm{y}$-axis correspond to DNA content and fraction of events, respectively. (B) The multiple myeloma cells treated with tomentosin $25 \mu \mathrm{M}$ or vehicle solution (DMSO 0.05\%) for 6,8,12, 18 and $24 \mathrm{~h}$ were blocked in the G2/M phase. Two-way ANOVA and Tukey's post hoc test were applied for the statistical analysis of the cell cycle. The bars represent the mean \pm SD of the percentage of three independent experiments (with a $\mathrm{P}<0.05$ ). ${ }^{*} \mathrm{P} \leq 0.0338$; ${ }^{* *} \mathrm{P} \leq 0.0037,{ }^{* * *} \mathrm{P} \leq 0.0001$.

Tomentosin effect on cell cycle in MM cell lines. To address whether the antiproliferative effect of tomentosin on MM cells was associated with cell cycle regulation, DNA cell cycle analysis by flow cytometry was performed in RPMI-8226 cells treated with tomentosin or vehicle (Fig. 3A). Incubation with tomentosin $(25 \mu \mathrm{M})$ for $6,8,12,18$ and 24 h showed a progressive decrease of cell number in S-phase at 18 and $24 \mathrm{~h}$ (at $24 \mathrm{~h}$, 5.23 vs. $17.68 \%$ in control, $\mathrm{P}<0.05$ ) and an increase of cell number in $\mathrm{G} 2 / \mathrm{M}$-phase that started at $12 \mathrm{~h}$ (at $24 \mathrm{~h}, 72.62$ vs. $38.86 \%$ in control, $\mathrm{P}<0.05$ ), accompanied by a corresponding decrease in the proportion of cells in G0/G1 (at $24 \mathrm{~h}, 19.67$ vs. $42.34 \%$ in control, $\mathrm{P}<0.05$ ) (Fig. 3B). These results revealed that $\mathrm{MM}$ cells treated with tomentosin were blocked in the G2/M phase. These data suggested that both cell cycle arrest and cell apoptosis could explain the antiproliferative effects of tomentosin and may result in the inhibition of RPMI-8226 cell viability.
Tomentosin effects on gene expression profiling in MM cell lines. To assess DEGs contributing to tomentosin effects on RPMI-8226 cells and identify its possible mechanisms of action, the HTG EdgeSeq Oncology Biomarker Panel was used to analyze the expression of 2,559 cancer-related genes by high-throughput mRNA quantitation analysis. Comparing global gene expression between RPMI-8226 cells treated with $25 \mu \mathrm{M}$ tomentosin or untreated (vehicle), 126 genes were shown to be differentially expressed. Specifically, 71 genes were upregulated and 53 genes were downregulated (Table SI).

An unsupervised hierarchical clustering analysis of 126 DEGs allowed to clearly separate tomentosin-treated RPMI-8226 cells vs. untreated cells (Fig. 4A). To investigate the biological role of the 126 DEGs deregulated by tomentosin in RPMI-8226 cells, a functional enrichment analysis was 

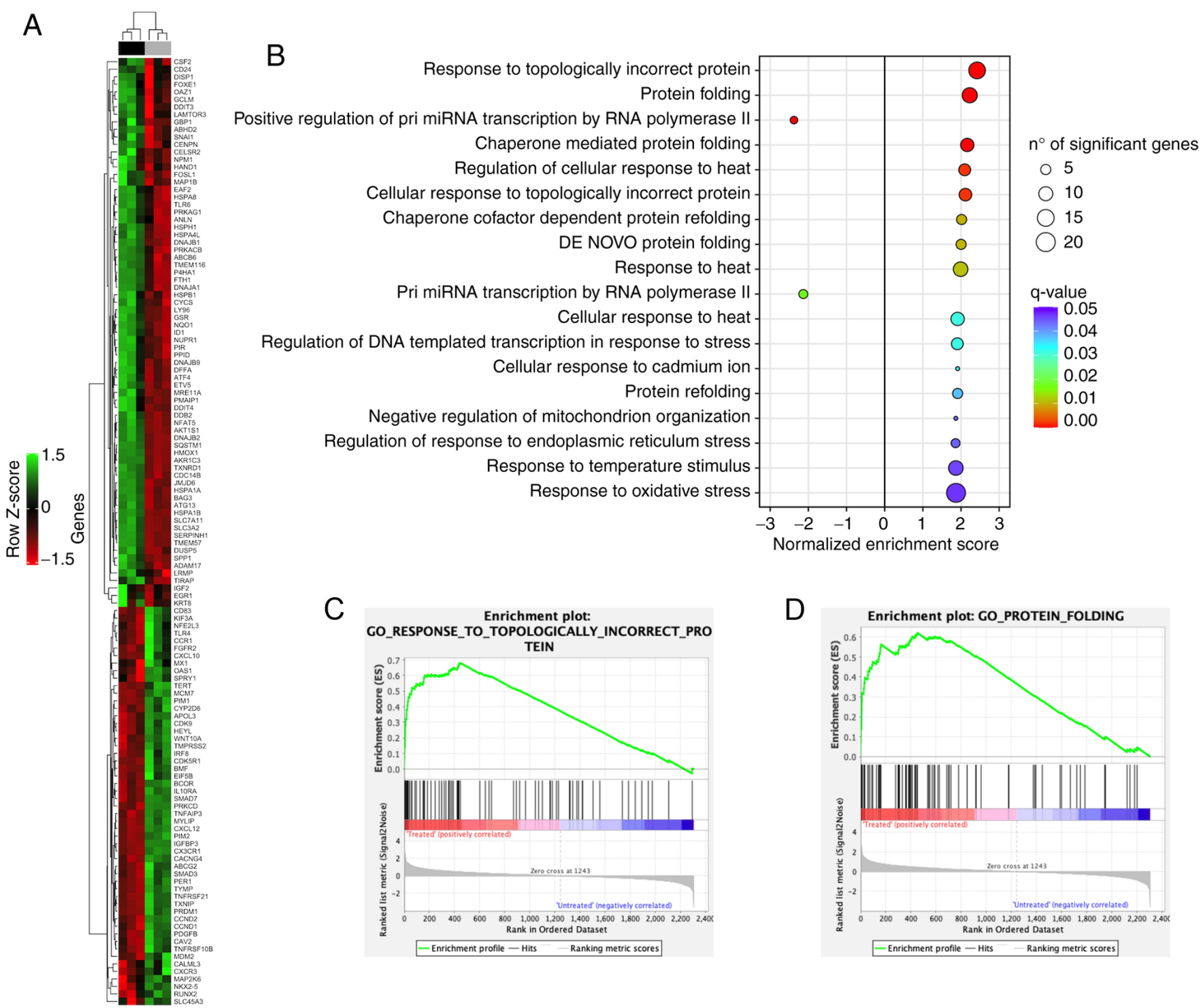

C
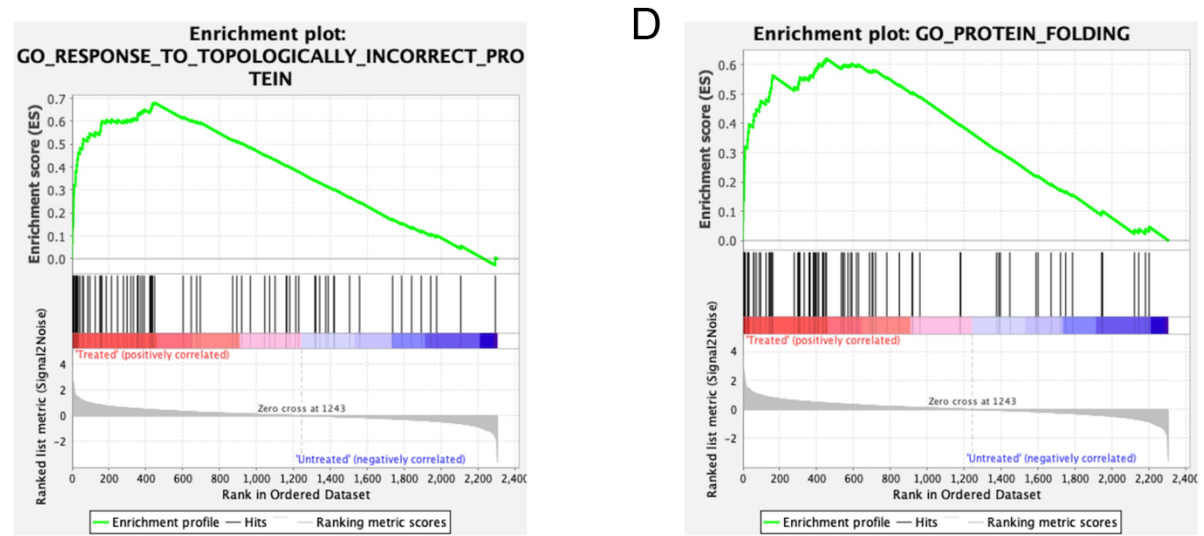

Figure 4. Changes in the expression of cancer-related genes in response to tomentosin treatment in RPMI- 8226 cells. (A) Heatmap showing the 126 differentially expressed genes after tomentosin treatment. Upper color bar represents sample classes; black represents treated sample group $(8 \mathrm{~h}$ treatment, $25 \mu \mathrm{M})$; grey represents untreated sample group (cells treated with vehicle solution). (B) Gene sets enriched by tomentosin treatment (false discovery rate $<0.05$ ). Positive NES indicates upregulated gene sets; negative NES indicates downregulated gene sets. (C and D) Gene Set Enrichment Analysis plots showing upregulation of 'Response to Topologically Incorrect Protein' pathway and 'Protein Folding' pathway. NES, normalized enrichment score.

performed. DEGs identified in tomentosin-treated RPMI-8226 were significantly involved in biological processes, such as 'response to topologically incorrect protein', 'protein folding', 'regulation of response to endoplasmic reticulum stress', 'response to heat' and 'response to oxidative stress' (Fig. 4B-D).

Table SII shows the list of DEGs involved in each biological process. Furthermore, the significant identified DEGs were enriched in proteins that have key roles in cellular pathways, such MAPK, p53, PI3K-Akt, Hedgehog, Hippo, WNT, Apelin and cell cycle, apoptosis, ferroptosis, immune-system, DNA damage response, protein processing in endoplasmic reticulum (ER), angiogenesis, osteoclast differentiation and signaling pathways regulating pluripotency of stem cells (Table SIII).

To address the systems biology and identify how tomentosin deregulates DEGs in MM from a systems perspective, all DEGs were analyzed using the STRING bioinformatics platform. Fig. 5 shows the interaction network of involved tomentosin-deregulated DEGs, represented by 125 nodes and 429 edges, an average node degree of 6.86. Besides, network analysis also showed that the clustering coefficient and PPI enrichment P-values were 0.534 and $<0.0001$, respectively, thus underlining the reliable robustness of the network.

To discover the functional connections between drugs, genes and diseases through the transitory features of common gene-expression changes, the 126 DEGs were submitted to the Connectivity Map online web tool. The results suggested that the mechanisms of tomentosin activity on RPMI-8226 cells may be similar to those exerted by heat shock protein (HSP) inhibitors (Fig. 6), considering that Tomentosin deregulates the expression of the same genes (ATF4, DDIT3, HSPA4L, HSPB1, HSPA1A, HSPA8, DNAJB1, DNAJB2, DNAJA1, SERPINH1, HSPH1, HSPA1B) affected by HSP inhibitors. 


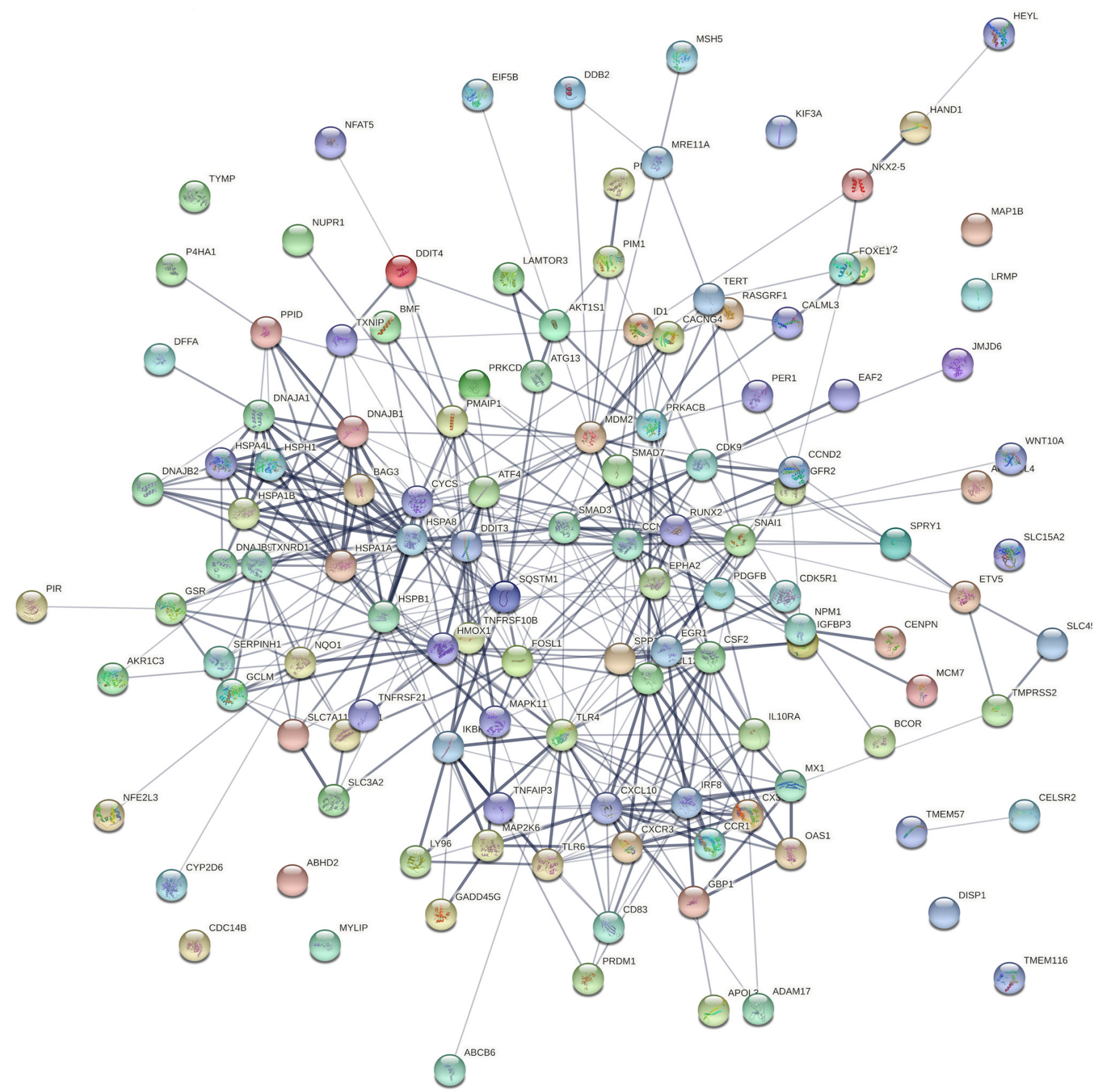

Figure 5. Genetic interaction network associated with tomentosin treatment in multiple myeloma based on Search Tool for the Retrieval of Interacting Genes platform.

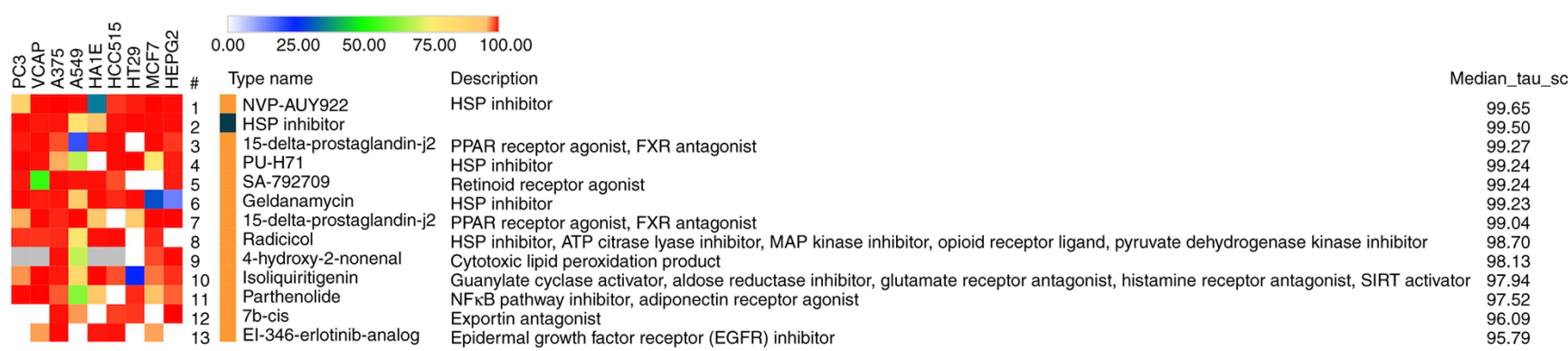

Figure 6. CMap analysis using differentially expressed genes after tomentosin treatment. CMap signatures with median connectivity (tau) score across nine cell lines $>95$ are shown. Connectivity score for each cell line is indicated in the heatmap on the left. Type of perturbagen is indicated in orange for compounds or dark blue for perturbational classes. CMap, Connectivity Map; HSP, heat shock protein. 


\section{Discussion}

Improvements in survival for patients with $\mathrm{MM}$ with recent diagnosis have been well-described according to randomized clinical trials (38-40) and assumed as a result of the higher use of autologous hematopoietic stem cell transplantation, as well as of the introduction of novel agents, specifically proteasome inhibitors and immunomodulatory agents (41-43). A previous population-based study in MM revealed that OS is increasing also among racial/ethnic minorities, although OS improvements are consistently limited to younger patients $<70$ years of age (38). Substantially, MM continues to represent an incurable disease due to the frequent development of drug resistance and to its intrinsic tendency to recur over time. Accordingly, the identification of further effective and potentially synergistic therapeutic agents that may overcome the strong collateral effects of drugs currently utilized in MM and their substantial inefficacy in elderly patients, still represents a landmark for patient outcomes.

Tomentosin and inuviscolide are natural potent bioactive compounds extracted from I. viscosa, identified as worthwhile therapeutic agents against various types of cancer. Our previous study demonstrated that $I$. viscosa extract exhibited powerful antiproliferative and cytotoxic activities on Raji cell line, showing a dose- and time-dependent decrease in cell viability, obtained by cell cycle arrest in the G2/M phase and an increase in cell apoptosis. The molecular mechanisms underlying such an antineoplastic activity are based on targeting and on downregulation of genes involved in cell cycle and apoptosis (19).

So far, the anti-neoplastic effects of sesquiterpene lactones on MM have not been studied. Thus, the present study aimed to investigate if sesquiterpene lactones may be responsible for the bioactivity of I. viscosa plants. This study showed that tomentosin exerts antiproliferative and cytotoxic activity against MM.1S and RPMI-8226 cell lines. In fact, the treatment of these cell lines with increasing concentrations of tomentosin showed a dose-dependent decrease in cell viability, paralleled by a reduction in cell proliferation due to an induction of cell cycle arrest in the G2/M phase. Moreover, a dose-dependent increase in cell apoptosis was observed As demonstrated in the present study, tomentosin promoted apoptosis-induced death mediated by both the death receptor and the mitochondrial pathways on RPMI-8226 cells. These findings suggested that both cell cycle arrest and cell apoptosis could be the primary mechanisms underlying the antiproliferative effects of tomentosin, resulting in the inhibition of RPMI-8226 cell viability. Tomentosin did not promote apoptosis-induced death mediated by both the death receptor and the mitochondrial pathways in MM.1S cell lines. The differences identified between the two MM cell lines should be dependent on wide heterogeneity that characterized the various MM cell lines produced. Specifically, RPMI-8226 cells are considered as well-molecularly characterized MM cells and represent MM at diagnosis, conversely MM.1S cells are less well-characterized and represent terminal tumor (44). Considering these differences, the results should be related to this heterogeneity, and it should be hypothesized that tomentosin is more efficient on tumors at the initial stages of development.
The current results are supported by previous studies, in which several anticancer properties have been attributed to tomentosin. Rozenblat et al (26) showed strong pro-apoptotic effects of both sesquiterpene in human aggressive melanoma cell lines, suggesting their potential pharmacological value. Moreover, tomentosin exerts anticancer effects mainly by inducing apoptotic death through different mechanisms in gastric cancer, cervical cancer and osteosarcoma (27-29). Recently, Yang et al (45) demonstrated that tomentosin induces apoptosis in human leukemia cells via the caspase-facilitated pro-apoptotic pathway, and inhibition of the NF-kB-stimulated Bcl-2. Of note, a recent in vivo study showed the antitumor effects of $I$. viscosa extract on skin carcinogenesis induced in mice by the inhibition of proteasome activity (46). The ingestion of I. viscosa extract in mice delayed the formation of skin papilloma and reduced their size and numbers (46).

In order to analyze the molecular mechanisms involved in the anti-cancer activity of tomentosin, a high-throughput mRNA quantitation analysis on 2,559 cancer-related genes was performed in the present study. A total of 126 DEGs showing different activities in human MM cell lines treated with tomentosin or untreated were identified.

Deregulation of various biological pathways is a hallmark in tumor pathogenesis. The current data showed that a number of DEGs and pivotal pathways involved in MM biology were deregulated by tomentosin treatment. The PPI network analysis demonsrtated that tomentosin treatment in human MM cell lines induced a downregulation of genes involved in pathways known to lead immune-system processes, such as cytokine-cytokine receptor interaction, chemokine signaling pathway, NF-kB signaling pathway, inflammatory mediator regulation of TRP channels, Toll-like receptor (TLR) signaling pathway and TNF signaling pathway. Of note, CCR1, CXCR1-3, CXCL10-12 and MAP2K6 were downregulated in human MM by tomentosin treatment. Recently, Zeissig et al (47) showed within in vivo experiments that CCR1 overexpression is a key driver of MM plasma cells escaping from the $\mathrm{BM}$ to circulation during MM progression. In addition, inhibition of CCR1 via therapeutic targeting or knockout reduces MM OPM2 or RPMI-8226 dissemination in intratibial xenograft models (47). Based on the mechanistical role of CCR1 in human MM, we could hypothesize that CCR1 downregulation induced by tomentosin treatment could potentially prevent MM progression and metastasization, thus blocking the development severe of osteolytic lesions (48). CXCR3 overexpression on tumor cells and regulatory immune cell populations has been associated with poor survival in patients affected by several subtypes of tumors (49-51). During the development of hematological tumors in BM, CXCR3 activation could induce natural killer (NK) cell mobilization from BM into peripheral blood, blocking their approach towards tumor micro-environment. In MM the upregulation of CXCR3 ligands is associated with the severity of the disease and with poor survival $(51,52)$. Bonanni et al (53) demonstrated that the inhibition of CXCR3/CXCL10 axis induces a powerful long-lasting antitumor effect of NK cell-based adoptive immunotherapy due to an increased accumulation in BM (53). These observations support the present results, which showed that tomentosin treatment inhibited the CXCR3/CXCL10 axis in MM, thus it may potentially be able to overcome the 
impairment of NK cell tumor infiltration and improve their effects within anti-cancer immunity.

TLRs are sensors for the innate immunity and initiators of adaptive immunity and are required for normal B lymphocyte activation (54). Previous studies have identified the role of TLR systems on malignant B cell proliferation, differentiation and apoptotic processes (55). Xu et al (56) showed that TLR4 and TLR 9 overexpression can induce the NF- $\kappa \mathrm{B}$ pathway, which produces the upregulation of IL6, thus promoting MM cell proliferation and survival. Phosphorylated MAP2K6, in response to inflammatory cytokines or environmental stress, i.e. after stimulation of the TLRs by pathogen-associated molecular pattern, activates p38-MAP-kinase, JNK and ERK pathways controlling cell cycle arrest, transcription activation and apoptosis (57). The TLR4 and MAP2K6 downregulation identified after tomentosin treatment in MM could be also concordant with a reduction of signaling pathways involved in the inflammatory process. Besides, MAP2K6 is also identified as a poor prognostic factor in MM (58).

IL10RA is a receptor with potent anti-inflammatory activity, which also improves survival of progenitor myeloid cells through the activation of major survival pathways, consisting of IRS-2 and PI3K/AKT pathways $(59,60)$. The IL10RA downregulation induced by tomentosin treatment in MM could be considered as likely responsible for decreasing cell survival.

The PPI network analysis demonstrated the downregulation of genes involved in pathways known to be implicated in cellular neoplastic processes, such as growth, proliferation, migration and invasion. However, the involvement of tomentosin in MM progression was based exclusively on gene expression profiling and enrichment analysis, representing a limitation of the present study. Importantly, these data showed the downregulation of CCND1 and CCND2 genes in $\mathrm{MM}$ cells treated with tomentosin, which may explain the anti-proliferative effects of tomentosin resulting in the inhibition of RPMI-8226 cell viability. The critical role of D-type cyclins in governing cell cycle entry and progression and their almost universal dysregulation in MM propose their central role in disease pathogenesis and biology (61).

Zhang et al (62) showed that RUNX2 was highly expressed in non-Hodgkin's lymphoma and MM cell lines promoting the proliferation and cell adhesion-mediated drug resistance (CAM-DR). The induction of RUNX2 downregulation reverses CAM-DR. Based on the current data, tomentosin could be considered as a RUNX2 inhibitor, thus representing a possible option to overcome drug resistance (62).

MCM7 is one of the most important subunits of the miniature chromosome maintenance (MCM) complex that participates in the cell cycle regulation from G1 to $S$ phase (63) in mRNA transcription and regulation of DNA damage $(64,65)$. Notably, Tian et al (66) silencing MCM7 in leukemia cells in vitro and in vivo experiments led to a significant decrease in proliferation, inhibition of cell cycle progression and enhancing apoptosis. Tomentosin could be proposed as a MCM7 inhibitor, therefore representing a suitable strategy for growth inhibition and apoptosis induction in MM.

The indirect mechanism to reduce or damage p53 activity is mediated by the overexpression of negative regulators. The interaction of MDM2 with p53 favors the translocation of p53 from the nucleus to the cytoplasm and its quick degradation by the proteasome (67). Consequently, p53 activation can be obtained by inhibiting the association of the protein with their negative regulators in tumors overexpressing them. The first molecule identified as a potent inhibitor of the p53-MDM2 interaction was nutlin (68). Nutlin-3 has a potent antitumor effect through the induction of apoptosis in different hematological tumor cells lines, including MM (69-71). The present results suggested that tomentosin promoted apoptosis-induced death on RPMI-8226 cells mediated by both the death receptor and the mitochondrial pathways. Besides, it could be possible that another mechanism of apoptosis-induced death and growth inhibition induced by Tomentosin is via deregulation of the MDM2 gene. Of note, the tomentosin-induced downregulation of SMAD7 and SMAD3 should strengthen the growth inhibition and apoptosis induction regulated by the TGF-b family pathway in neoplastic cells (72).

MM cells treated with tomentosin also show deregulation of CDK9, which belongs to the CDK-transcriptional regulator sub-group. CDK9 is responsible for the synthesis of Mcl-1 and XIAP antiapoptotic proteins, and maintaining the conditions for cancer cell survival (73). Recently, novel 2,4-disubstituted pyrimidine derivatives showing CDK9 inhibitory and antiproliferative effects on RPMI-8226 were synthesized (74).

Gene expression profiling analysis of MM cell lines treated with tomentosin in the present study showed the upregulation of DnaJ family of proteins and HSP-70, which support protein folding and misfolded proteins degradation, intracellular trafficking, modulating signaling pathways and regulating immune responses $(75,76)$. Considering that cytoplasmic HSP-70s, inducible Hsp72 and constitutively expressed Hsc70 are regularly upregulated in myeloma, and Hsp70 inhibition is also successful in influencing myeloma cell death (77-79), the current data suggested that tomentosin did not directly affect their expression in our experimental conditions.

Notably, the current study demonstrated that tomentosin induces the upregulation of ATF4 and DDIT3 genes in MM cells, whose proteins are enriched in protein processing in the ER pathway and protein folding process. Accumulation of misfolded proteins, typical of MM cells, in the ER lumen causes ER stress and activation of the unfolded protein response signaling pathway, which triggers downstream pathways to inhibit protein translation and increases protein folding activity expanding chaperone expression levels (80). The chronic activation of the ER stress response can trigger apoptotic signals, leading to the expression of downstream signaling, which damage the target cells (81).

The increased ATF4 and DDIT3 expression induced by tomentosin in MM may be responsible for the activation of the unfolded protein response PERK/eIF2a/ATF4/DDIT3 pathway. The activation of the transcription factor ATF4, which further activates the proapoptotic CHOP (DDIT3), suggests that in the presence of tomentosin the protective cell mechanisms activated by the unfolded protein response signaling is not sufficient to restore normal ER function and apoptois is induced. This hypothesis was supported by the results obtained from functional connections analysis executed using the Connectivity Map tool, which suggested that the mechanism of tomentosin in RPMI-8226 cells may be similar to those exerted by HSP inhibitors. 
Our future investigations will include in vivo experiments to analyze the molecular mechanisms by which tomentosin induces pharmacological effects in human MM, supported by the gene expression profile and enrichment analyses obtained by tomentosin treatment on MM cell lines.

To sum up, the present study demonstrated that tomentosin has a potent antitumor activity on MM cells through inhibition of cell proliferation and induction of cell apoptosis. Furthermore, through the execution of a gene expression profiling analysis and the construction of a genetic interaction network, the molecular mechanisms responsible for the effects of tomentosin on MM were explored. Specifically, tomentosin induces the downregulation of genes enriched in immune-system pathways, as well as pathways that favor proliferation, growth, migration and invasion processes. Of note, tomentosin may inhibit the growth of MM through the induction of apoptosis by upregulation of the PERK/eIF2a/ATF4/DDIT3 pathway. These results suggested that tomentosin could be considered a potential natural drug with limited toxicity and relevant antitumor activity in the therapeutic armamentarium available for patients with MM.

\section{Acknowledgements}

Not applicable.

\section{Funding}

Financial support was provided by grants from the 'Associazione Italiana contro le Leucemie-linfomi e myeloma' (AIL), and the research was funded by Fondazione di Sardegna, Italy.

\section{Availability of data and materials}

All data generated or analyzed during this study are included in this published article.

\section{Authors' contributions}

PV, GP, CF, LB, MRDM and LP were responsible for conceptualization of the present study. PV, RM, GG, LS, VB and MRM performed the experiments. IM, FPF and MRDM conducted the formal analysis of the data, and wrote the original draft preparation. CF, LP, GP and LB reviewed and edited the manuscript. GP, CF and LP were responsible for funding acquisition. IM and FPF confirm the authenticity of all the raw data. All authors read and approved the final version of the manuscript.

\section{Ethics approval and consent to participate}

Not applicable.

\section{Patient consent for publication}

Not applicable.

\section{Competing interests}

The authors declare that they have no competing interests.

\section{References}

1. Kumar SK, Dispenzieri A, Lacy MQ, Gertz MA, Buadi FK, Pandey S, Kapoor P, Dingli D, Hayman SR, Leung N, et al: Continued improvement in survival in multiple myeloma: Changes in early mortality and outcomes in older patients. Leukemia 28: 1122-1128, 2014.

2. Röllig C, Knop S and Bornhäuser M: Multiple myeloma. Lancet 385: 2197-2208, 2015.

3. van de Donk NWCJ, Pawlyn C and Yong KL: Multiple myeloma. Lancet 397: 410-427, 2021.

4. Kyle RA and Rajkumar SV: Drug therapy: Multiple myeloma. N Engl J Med 351: 1860-1873, 2004

5. Roodman GD: Pathogenesis of myeloma bone disease. Leukemia 23: 435-441, 2009.

6. Raje NS, Bhatta S and Terpos E: Role of the RANK/RANKL pathway in multiple myeloma. Clin Cancer Res 25: 12-20, 2019.

7. KyleRA,ChildJA, Anderson K,Barlogie B,Bataille R,BensingerW, Bladé J, Boccadoro M, Dalton W, Dimopoulos M, et al: Criteria for the classification of monoclonal gammopathies, multiple myeloma and related disorders: A report of the international myeloma working group. Br J Haematol 121: 749-757, 2003.

8. Maiese EM, Evans KA, Chu BC and Irwin DE: Temporal trends in survival and healthcare costs in patients with multiple myeloma in the United States. Am Heal Drug Benefits 11: 39-46, 2018.

9. Fonseca R, Abouzaid S, Bonafede M, Cai Q, Parikh K, Cosler L and Richardson P: Trends in overall survival and costs of multiple myeloma, 2000-2014. Leukemia 31: 1915-1921, 2017.

10. Durie BGM, Hoering A, Abidi MH, Rajkumar SV, Epstein J, Kahanic SP, Thakuri M, Reu F, Reynolds CM, Sexton R, et al: Bortezomib with lenalidomide and dexamethasone versus lenalidomide and dexamethasone alone in patients with newly diagnosed myeloma without intent for immediate autologous stem-cell transplant (SWOG S0777): A randomised, open-label, phase 3 trial. Lancet 389: 519-527, 2017.

11. Child JA, Morgan GJ, Davies FE, Owen RG, Bell SE, Hawkins K, Brown J, Drayson MT and Selby PJ; Medical Research Council Adult Leukaemia Working Party: High-dose chemotherapy with hematopoietic stem-cell rescue for multiple myeloma. N Engl J Med 348: 1875-1883, 2003.

12. McCarthy PL, Holstein SA, Petrucci MT, Richardson PG, Hulin C, Tosi P, Bringhen S, Musto P, Anderson KC, Caillot $\mathrm{D}$, et al: Lenalidomide maintenance after autologous stem-cell transplantation in newly diagnosed multiple myeloma: A meta-analysis. J Clin Oncol 35: 3279-3289, 2017.

13. Bergsagel PL: Where we were, where we are, where we are going: Progress in multiple myeloma. Am Soc Clin Oncol Educ Book: 199-203, 2014.

14. Teoh PJ and Chng WJ: CAR T-cell therapy in multiple myeloma: More room for improvement. Blood Cancer J 11: 84, 2021.

15. Ludwig H, Delforge M, Facon T, Einsele H, Gay F, Moreau P, Avet-Loiseau H, Boccadoro M, Hajek R, Mohty M, et al: Prevention and management of adverse events of novel agents in multiple myeloma: A consensus of the European myeloma network. Leukemia 32: 1542-1560, 2018.

16. Pulte D, Redaniel MT, Brenner H,Jansen L and Jeffreys M: Recent improvement in survival of patients with multiple myeloma: Variation by ethnicity. Leuk Lymphoma 55: 1083-1089, 2014.

17. Kristinsson SY, Anderson WF and Landgren O: Improved long-term survival in multiple myeloma up to the age of 80 years. Leukemia 28: 1346-1348, 2014.

18. Giuliani N, Accardi F, Marchica V, Dalla Palma B, Storti P, Toscani D, Vicario E and Malavasi F: Novel targets for the treatment of relapsing multiple myeloma. Expert Rev Hematol 12: 481-496, 2019.

19. Virdis P, Migheli R, Galleri G, Fancello S, Cadoni MPL, Pintore G, Petretto GL, Marchesi I, Fiorentino FP, di Francesco A, et al: Antiproliferative and proapoptotic effects of Inula viscosa extract on Burkitt lymphoma cell line. Tumor Biol 42: 1010428319901061, 2020.

20. Barbetti P, Chiappini I, Fardella G and Menghini A: A new eudesmane acid from Dittrichia (Inula) viscosa. Planta Med 51: 471,1985

21. Lauro L and Rolih C: Observations and research on an extract of Inula viscosa Ait. Boll Soc Ital Biol Sper 66: 829-834, 1990 (In Italian).

22. Lev E and Amar Z: Ethnopharmacological survey of traditional drugs sold in Israel at the end of the 20th century. J Ethnopharmacol 72: 191-205, 2000. 
23. Yaniv Z, Dafni A, Friedman J and Palevitch D: Plants used for the treatment of diabetes in Israel. J Ethnopharmacol 19: 145-151, 1987.

24. Al-Qura'n S: Ethnopharmacological survey of wild medicinal plants in Showbak, Jordan. J Ethnopharmacol 123: 45-50, 2009.

25. Messaoudi M, Chahmi N, El-Mzibri M, Gmouh S, Amzazi S, Benbacer L and El-Hassouni M: Cytotoxic Effect and chemical composition of Inula viscosa from three different regions of morocco. Eur J Med Plants 16: 1-9, 2016.

26. Rozenblat S, Grossman S, Bergman M, Gottlieb H, Cohen Y and Dovrat S: Induction of $\mathrm{G} 2 / \mathrm{M}$ arrest and apoptosis by sesquiterpene lactones in human melanoma cell lines. Biochem Pharmacol 75: 369-382, 2008.

27. Yang H, Zhao H, Dong X, Yang Z and Chang W: Tomentosin induces apoptotic pathway by blocking inflammatory mediators via modulation of cell proteins in AGS gastric cancer cell line. J Biochem Mol Toxicol 34: e22501, 2020.

28. Merghoub N, El Btaouri H, Benbacer L, Gmouh S, Trentesaux C, Brassart B, Attaleb M, Madoulet C, Wenner T, Amzazi S, et al Tomentosin induces telomere shortening and caspase-dependant apoptosis in cervical cancer cells. J Cell Biochem 118: 1689-1698, 2017.

29. Lee CM, Lee J, Nam MJ, Choi YS and Park SH: Tomentosin displays anti-carcinogenic effect in human osteosarcoma MG-63 cells via the induction of intracellular reactive oxygen species. Int J Mol Sci 20: 1508, 2019.

30. Ihaka R and Gentleman R: R: A language for data analysis and graphics. J Comput Graph Stat 5: 299-314, 1996.

31. Ellis B, Gentleman R, Hahne F, Le Meur N, Sarkar D and Jiang M: flowViz: Visualization for flow cytometry. R package version 1.56.0, 2021. https://www.bioconductor.org/packages/ release/bioc/html/flowViz.html.

32. Love MI, Huber W and Anders S: Moderated estimation of fold change and dispersion for RNA-seq data with DESeq2. Genome Biol 15: 550, 2014

33. Subramanian A, Tamayo P, Mootha VK, Mukherjee S, Ebert BL, Gillette MA, Paulovich A,Pomeroy SL, Golub TR, Lander ES and Mesirov JP: Gene set enrichment analysis: A knowledge-based approach for interpreting genome-wide expression profiles. Proc Natl Acad Sci USA 102: 15545-15550, 2005.

34. Ashburner M, Ball CA, Blake JA, Botstein D, Butler H, Cherry JM, Davis AP, Dolinski K, Dwight SS, Eppig JT, et al: Gene ontology: Tool for the unification of biology. The gene ontology consortium. Nat Genet 25: 25-29, 2000.

35. Carbon S, Douglass E, Good BM,Unni DR, Harris NL, Mungall CJ, Basu S and Elser J: The gene ontology resource: Enriching a GOld mine. Nucleic Acids Res 49D: D325-D334, 2021.

36. Kanehisa M and Goto S: KEGG: Kyoto encyclopedia of genes and genomes. Nucleic Acids Res 28: 27-30, 2000.

37. Igney FH and Krammer PH: Death and anti-death: Tumour resistance to apoptosis. Nat Rev Cancer 2: 277-288, 2002.

38. Costa LJ, Brill IK, Omel J, Godby K, Kumar SK and Brown EE: Recent trends in multiple myeloma incidence and survival by age, race, and ethnicity in the United States. Blood Adv 1: 282-287, 2017.

39. Cavo M, Tacchetti P, Patriarca F, Petrucci MT, Pantani L, Galli M, Di Raimondo F, Crippa C, Zamagni E, Palumbo A, et al: Bortezomib with thalidomide plus dexamethasone compared with thalidomide plus dexamethasone as induction therapy before, and consolidation therapy after, double autologous stem-cell transplantation in newly diagnosed multiple myeloma: A randomised 3 study. Lancet 376: 2075-2085, 2010.

40. Miguel JS, Weisel K, Moreau P, Lacy M, Song K, Delforge M, Karlin L, Goldschmidt H, Banos A, Oriol A, et al: Pomalidomide plus low-dose dexamethasone versus high-dose dexamethasone alone for patients with relapsed and refractory multiple myeloma (MM-003): A randomised, open-label, phase 3 trial. Lancet Oncol 14: 1055-1066, 2013.

41. Singhal S, Mehta J, Desikan R, Ayers D, Roberson P, Eddlemon P, Munshi N, Anaissie E, Wilson C, Dhodapkar M, et al: Antitumor activity of thalidomide in refractory multiple myeloma. N Engl J Med 341: 1565-1571, 1999.

42. Palumbo A, Hajek R, Delforge M, Kropff M, Petrucci MT, Catalano J, Gisslinger H, Wiktor-Jędrzejczak W, Zodelava M, Weisel K, et al: Continuous lenalidomide treatment for newly diagnosed multiple myeloma. N Engl J Med 366: 1759-1769, 2012

43. Dimopoulos M, Spencer A, Attal M, Prince HM, Harousseau JL, Dmoszynska A, San Miguel J, Hellmann A, Facon T, Foà R, et al: Lenalidomide plus dexamethasone for relapsed or refractory multiple myeloma. N Engl J Med 357: 2123-2132, 2007.
44. Drexler HG and MacLeod RAF: Malignant hematopoietic cell lines: In vitro models for the study of plasmacytoid dendritic cell leukemia. Leuk Res 33: 1166-1169, 2009.

45. Yang L, Xie J, Almoallim HS, Alharbi SA and Chen Y: Tomentosin inhibits cell proliferation and induces apoptosis in MOLT-4 leukemia cancer cells through the inhibition of mTOR/PI3K/Akt signaling pathway. J Biochem Mol Toxicol 35: e22719, 2021.

46. El Yaagoubi OM, Lahmadi A, Bouyahya A, Filali H, Samaki H, El Antri S and Aboudkhil S: Antitumor effect of Inula viscosa extracts on DMBA-induced skin carcinoma are mediated by proteasome inhibition. Biomed Res Int 2021: 6687589, 2021.

47. Zeissig MN, Hewett DR, Panagopoulos V, Mrozik KM, To LB, Croucher PI, Zannettino ACW and Vandyke K: Expression of the chemokine receptor CCR 1 promotes the dissemination of multiple myeloma plasma cells in vivo. Haematologica: Nov 5 , 2020 (Epub ahead of print). doi: 10.3324/haematol.2020.253526.

48. Dairaghi DJ, Oyajobi BO, Gupta A, McCluskey B, Miao S, Powers JP, Seitz LC, Wang Y, Zeng Y, Zhang P, et al: CCR1 blockade reduces tumor burden and osteolysis in vivo in a mouse model of myeloma bone disease. Blood 120: 1449-1457, 2012.

49. Ganghammer S, Gutjahr J, Hutterer E, Krenn PW, Pucher S, Zelle-Rieser C, Jöhrer K, Wijtmans M, Leurs R, Smit MJ, et al: Combined CXCR3/CXCR4 measurements are of high prognostic value in chronic lymphocytic leukemia due to negative co-operativity of the receptors. Haematologica 101: e99-e102, 2016.

50. Mulligan AM, Raitman I, Feeley L, Pinnaduwage D, Nguyen LT, O'Malley FP, Ohashi PS and Andrulis IL: Tumoral lymphocytic infiltration and expression of the chemokine CXCL10 in breast cancers from the ontario familial breast cancer registry. Clin Cancer Res 19: 336-346, 2013.

51. Bolomsky A, Schreder M, Hübl W, Zojer N, Hilbe W and Ludwig H: Monokine induced by interferon gamma (MIG/CXCL9) is an independent prognostic factor in newly diagnosed myeloma. Leuk Lymphoma 57: 2516-2525, 2016.

52. Guillerey C, Huntington ND and Smyth MJ: Targeting natural killer cells in cancer immunotherapy. Nat Immunol 17: 1025-1036, 2016

53. Bonanni V, Antonangeli F, Santoni A and Bernardini G: Targeting of CXCR3 improves anti-myeloma efficacy of adoptively transferred activated natural killer cells. J Immunother Cancer 7: 290, 2019.

54. Vijay K: Toll-like receptors in immunity and inflammatory diseases: Past, present, and future. Int Immunopharmacol 59: 391-412, 2018.

55. Chiron D, Bekeredjian-Ding I, Pellat-Deceunynck C, Bataille R and Jego G: Toll-like receptors: Lessons to learn from normal and malignant human B cells. Blood 112: 2205-2213, 2008.

56. Xu Y, Zhao Y, Huang H, Chen G, Wu X, Wang Y, Chang W, Zhu Z, Feng Y and Wu D: Expression and function of toll-like receptors in multiple myeloma patients: Toll-like receptor ligands promote multiple myeloma cell growth and survival via activation of nuclear factor-kappaB. Br J Haematol 150: 543-553, 2010.

57. Rossi D: Role of MYD88 in lymphoplasmacytic lymphoma diagnosis and pathogenesis. Hematology Am Soc Hematol Educ Program 2014: 113-118, 2014.

58. de Boussac H, Bruyer A, Jourdan M, Maes A, Robert N, Gourzones C, Vincent L, Seckinger A, Cartron G, Hose D, et al: Kinome expression profiling to target new therapeutic avenues in multiple myeloma. Haematologica 105: 784-795, 2020.

59. Crawley JB, Williams LM, Mander T, Brennan FM and Foxwell BMJ: Interleukin-10 stimulation of phosphatidylinositol 3-kinase and p70 S6 kinase is required for the proliferative but not the antiinflammatory effects of the cytokine. J Biol Chem 271: 16357-16362, 1996.

60. Zhou JH, Broussard SR, Strle K, Freund GG, Johnson RW, Dantzer R and Kelley KW: IL-10 inhibits apoptosis of promyeloid cells by activating insulin receptor substrate-2 and phosphatidylinositol 3'-kinase. J Immunol 167: 4436-4442, 2001.

61. Zhan F, Huang Y, Colla S, Stewart JP, Hanamura I, Gupta S, Epstein J, Yaccoby S, Sawyer J, Burington B, et al: The molecular classification of multiple myeloma. Blood 108: 2020-2028, 2006.

62. Zhang PP, Wang YC, Cheng C, Zhang F, Ding DZ and Chen DK: Runt-related transcription factor 2 influences cell adhesion-mediated drug resistance and cell proliferation in B-cell non-Hodgkin's lymphoma and multiple myeloma. Leuk Res 92: 106340, Mar 9, 2020.

63. Luo JH: Oncogenic activity of MCM7 transforming cluster. World J Clin Oncol 2: 120-124, 2011. 
64. Cortez D, Glick G and Elledge SJ: Minichromosome maintenance proteins are direct targets of the ATM and ATR checkpoint kinases. Proc Natl Acad Sci USA 101: 10078-10083, 2004.

65. Tsao CC, Geisen C and Abraham RT: Interaction between human MCM7 and Rad17 proteins is required for replication checkpoint signaling. EMBO J 23: 4660-4669, 2004.

66. Tian L, Liu J, Xia GH and Chen BA: RNAi-mediated knockdown of MCM7 gene on CML cells and its therapeutic potential for leukemia. Med Oncol 34: 21, 2017.

67. Moll UM and Petrenko O: The MDM2-p53 interaction. Mol Cancer Res 1: 1001-1008, 2003.

68. Vassilev LT, Vu BT, Graves B, Carvajal D, Podlaski F, Filipovic Z, Kong N, Kammlott U, Lukacs C, Klein C, et al: In vivo activation of the p53 pathway by small-molecule antagonists of MDM2. Science 303: 844-848, 2004.

69. Teoh PJ, Chung TH, Sebastian S, Choo SN, Yan J, Ng SB, Fonseca R and Chng WJ: P53 haploinsufficiency and functional abnormalities in multiple myeloma. Leukemia 28: 2066-2074, 2014.

70. Saha MN, Qiu L and Chang H: Targeting p53 by small molecules in hematological malignancies. J Hematol Oncol 6: 23, 2013.

71. Teoh PJ and Chng WJ: P53 abnormalities and potential therapeutic targeting in multiple myeloma. Biomed Res Int 2014 717919, 2014

72. Halder SK, Beauchamp RD and Datta PK: Smad7 induces tumorigenicity by blocking TGF-beta-induced growth inhibition and apoptosis. Exp Cell Res 307: 231-246, 2005.

73. Chen R, Wierda WG, Chubb S, Hawtin RE, Fox JA, Keating MJ, Gandhi V and Plunkett W: Mechanism of action of SNS-032, a novel cyclin-dependent kinase inhibitor, in chronic lymphocytic leukemia. Blood 113: 4637-4645, 2009.

74. Czudor Z, Balogh M, Bánhegyi P, Boros S, Breza N, Dobos J, Fábián M, Horváth Z, Illyés E, Markó $\mathrm{P}$, et al: Novel compounds with potent CDK9 inhibitory activity for the treatment of myeloma. Bioorganic Med Chem Lett 28: 769-773, 2018.
75. Hartl FU: Molecular chaperones in cellular protein folding. Nature 381: 571-580, 1996.

76. Muralidharan S and Mandrekar P: Cellular stress response and innate immune signaling: Integrating pathways in host defense and inflammation. J Leukoc Biol 94: 1167-1184, 2013.

77. Chatterjee M, Andrulis M, Stühmer T, Müller E, Hofmann C, Steinbrunn T, Heimberger T, Schraud H, Kressmann S, Einsele $\mathrm{H}$ and Bargou RC: The PI3K/Akt signaling pathway regulates the expression of Hsp70, which critically contributes to Hsp90-chaperone function and tumor cell survival in multiple myeloma. Haematologica 98: 1132-1141, 2013.

78. Zhang L, Fok JJL, Mirabella F, Aronson LI, Fryer RA, Workman P, Morgan GJ and Davies FE: Hsp70 inhibition induces myeloma cell death via the intracellular accumulation of immunoglobulin and the generation of proteotoxic stress. Cancer Lett 339: 49-59, 2013.

79. Braunstein MJ, Scott SS, Scott CM, Behrman S, Walter P, Wipf P, Coplan JD, Chrico W, Joseph D, Brodsky JL and Batuman O: Antimyeloma effects of the heat shock protein 70 molecular chaperone inhibitor MAL3-101. J Oncol 2011: 232037, 2011.

80. Workman P and Davies FE: A stressful life (or death): Combinatorial proteotoxic approaches to cancer-selective therapeutic vulnerability. Oncotarget 2: 277-280, 2011.

81. Tiku V, Tan MW and Dikic I: Mitochondrial functions in infection and immunity: (Trends in Cell Biology 30, 263-275, 2020). Trends Cell Biol 30: 748, 2020.

(i) (9) This work is licensed under a Creative Commons Attribution-NonCommercial-NoDerivatives 4.0 International (CC BY-NC-ND 4.0) License. 